\title{
EVALUATION OF PAEDIATRIC BLUNT ABDOMEN TRAUMA PATIENTS PRESENTING TO THE EMERGENCY ROOM
}

\author{
Turgut Dolanbay ${ }^{1} \odot$, Nail Aksoy ${ }^{2} \odot$, Huseyin Fatih Gul ${ }^{3} \odot$, Murat Aras $^{1}$ \\ 'Department of Emergency Medicine, Kafkas University Health Research and Application Hospital, Kars, Turkey \\ ${ }^{2}$ Kafkas University Medical School, Department of Paediatric Surgery, Kars Turkey \\ ${ }^{3}$ Kafkas University Medical School, Department of Medical Biochemistry, Kars Turkey
}

\begin{abstract}
INTRODUCTION: In paediatric cases, trauma remains the most cause of morbidity and disability. Although abdominal trauma is observed less frequently in paediatric cases than isolated head trauma, it is still the leading cause of morbidity and mortality among children. Previous studies at the national level have either focused on blunt abdominal trauma in all age groups or other traumas at paediatric level. The studies targeting solely paediatric abdominal blunt trauma cases have not yet been evaluated. The aim of this study was to analyse and report the demographic characteristics, causes of trauma, developed pathologies, treatment approaches, and mortality rates in patients presenting to our emergency department with blunt abdominal trauma.
\end{abstract}

MATERIAL AND METHODS: The present study was designed as a retrospective study of 36 paediatric patients admitted to the Emergency Department of Kars Harakani State Hospital with blunt abdominal trauma between 2018 and 2019.

RESULTS: In the abdominal region, the most commonly injured organ was the liver (22 cases, 52.4\%), while $13(31 \%)$ cases had splenic trauma. Thirty-one (73.8\%) patients had other body injuries in addition to the abdominal trauma, the most common of which were fractures (15 patients, 35.7\%) and lung traumas (12 patients, 28.6\%).

CONCLUSIONS: The organs that are damaged during the injury and the parameters that can be used to detect them provide important data for the rapid interference and treatment of life-threatening situations.

KEY WORDS: emergency department; blunt abdominal trauma; paediatric cases; morbidity

Disaster Emerg Med J 2020; 5(1): 19-23

\section{INTRODUCTION}

Trauma-related deaths are the third most common cause of mortality after cardiovascular diseases and cancer in all age groups [1]. In paediatric cases, the situation is more severe. Despite increasing awareness and prevention efforts, trauma remains the most prevalent cause of death and disability in children [2]. According to United States national paediatric trauma statistics, approximately 1.5 million children are injured each year due to trauma, resulting in 500,000 children being treated in hospitals, 120,000 children with permanent disability, and 20,000 deaths $[2,3]$.

In general, the most common causes of trauma have been reported as motor vehicle accidents, falls, firearms, sharp object injuries, and burns [4]. Although abdominal trauma is seen less frequently in isolated paediatric cases, it is still the leading cause of morbidity and mortality in children.

Due to the anatomical, physiological, psychological, and epidemiological differences between 
children and adults, early childhood injuries have been proposed to be considered separately from adult abdominal trauma [1]. Children, unlike adults, undergo continuous growth and change. There are age-related limitations in their ability to understand their injuries, and to cooperate and communicate during diagnosis and treatment. Therefore, it is important to evaluate these cases separately. Abdominal injury may be difficult to identify in children with low levels of consciousness or at the preverbal stage, and these injuries may not be detected initially [5]. In Turkey, the first interventions are conducted by the emergency services rather than in special paediatric trauma centres for injured children [4]. Identifying the main problems regarding blunt abdominal injury along with the detailed analysis of the case type will enable emergency clinicians to be aware of the current problems during the diagnosis and provide an expedited treatment of traumas while providing care for such cases.

Previous studies at the national level have focused on either blunt abdominal trauma $[6,7]$ or other paediatric trauma $[4,8]$. Evaluation and reporting of cases solely on paediatric abdominal blunt trauma cases are rather rare and will provide invaluable data on the major problems and case patterns related to paediatric blunt abdominal injury.

The aim of this study was to analyse and report the demographic characteristics, causes of trauma, developed pathologies, treatment approaches, and mortality rates of patients presenting to our emergency department with blunt abdominal trauma.

\section{MATERIAL AND METHODS}

The present study was designed as a retrospective study of 42 paediatric cases admitted to Kars Harakani State Hospital Emergency Department with blunt abdominal trauma between 2015 and 2019. This study was conducted after the approval of Kafkas University Faculty of Medicine Clinical Research Ethics Committee with decision number 30/03/2015-30/03/2019. The following were evaluated: age, gender, event occurrence, month of the event, time of admission, blood values at the time of first admission, presence of accompanying trauma, treatment, hospitalisation, and mortality rates. Alanine aminotransferase (ALT), aspartate aminotransferase (AST), white blood cell count (WBC), and haemoglobin (HGB) levels of the patients were also recorded. Nominal variables were expressed in numbers and percentages. Student's t-test was performed for comparison of means in continuous variables. Statistical analysis programme SAS 9.2 (SAS Institute, Cary, NC) was used for all analyses. $\mathrm{P}<0.05$ was accepted as statistically significant throughout the experiment.

\section{RESULTS}

Of the 42 paediatric cases evaluated, 32 (76.2\%) were male and $10(23.8 \%)$ were female. While the mean age of paediatric patients was 7.46 years, $19 \%$ of the patients were in the 0-6 years age group, $38.1 \%$ were in the $7-12$ years age group, and $42.9 \%$ were in the 13-18 years age range (Tab. 1).

The most common cause of paediatric blunt abdominal trauma was falls (24 patients, 57.2\%). Motor vehicle accidents were the second most common cause of injury (12 patients, 28.5\%). Motor vehicle accidents were subsequently classified and evaluated

\begin{tabular}{|c|c|c|c|}
\hline Parameter & Groups & No. & $\%$ \\
\hline \multirow[t]{3}{*}{ Age } & $0-6$ years old & 8 & 19.0 \\
\hline & $7-12$ years old & 16 & 38.1 \\
\hline & $13-18$ years old & 18 & 42.9 \\
\hline \multirow[t]{2}{*}{ Gender } & Female & 10 & 23.8 \\
\hline & Male & 32 & 76.2 \\
\hline \multirow{5}{*}{$\begin{array}{l}\text { Cause of } \\
\text { trauma }\end{array}$} & Out-of-vehicle traffic accident & 7 & 16.6 \\
\hline & In-vehicle traffic accident & 5 & 11,9 \\
\hline & Occupational accident & 1 & 2.4 \\
\hline & Falling & 24 & 57.2 \\
\hline & Firearm/Sharp object & 5 & 11.9 \\
\hline \multirow{4}{*}{$\begin{array}{l}\text { Time of } \\
\text { trauma }\end{array}$} & $6: 00-12: 00$ & 10 & 23.8 \\
\hline & 12:01-18:00 & 17 & 40.5 \\
\hline & 18:01-00:00 & 12 & 28.6 \\
\hline & 00:00-6:00 & 3 & 7.1 \\
\hline \multirow{4}{*}{$\begin{array}{l}\text { Length } \\
\text { of stay in } \\
\text { hospital }\end{array}$} & $0-24$ hours & 4 & 9.5 \\
\hline & $25-72$ hours & 8 & 19.0 \\
\hline & 73 hours-1 week & 9 & 21.5 \\
\hline & 1 week & 21 & 50 \\
\hline
\end{tabular}




\begin{tabular}{|c|c|c|}
\hline & No. & $\%$ \\
\hline \multicolumn{3}{|l|}{ Number of organs affected by trauma } \\
\hline Single & 8 & 19.0 \\
\hline Multi-organ & 31 & 73.8 \\
\hline No trauma & 3 & 7.2 \\
\hline \multicolumn{3}{|l|}{ Primary trauma location $†$} \\
\hline Liver & 22 & 52.4 \\
\hline Spleen & 13 & 31.0 \\
\hline Stomach & 1 & 2.4 \\
\hline Pancreas & 1 & 2.4 \\
\hline Intestines & 3 & 7.1 \\
\hline Perineum & 1 & 2.4 \\
\hline \multicolumn{3}{|l|}{ Secondary trauma location $†$} \\
\hline Skin & 3 & 7.1 \\
\hline Lungs & 12 & 28.6 \\
\hline Cranial haematoma/defect/fracture & 6 & 14.3 \\
\hline Other fractures & 15 & 35.7 \\
\hline Pneumothorax and diaphragm rupture & 3 & 7.1 \\
\hline
\end{tabular}

and an occupational accident occurred in one case (Tab. 1).

Time of injury was evaluated in four different quarters, and injuries were present in all four quarters of the day. However, a total of $17(40.5 \%)$ cases occurred in the afternoon (12:01-18:00), while $12(28.6 \%)$ incidences occurred in the evening (18:01-00:00). Only three cases (7.1\%) occurred from midnight to morning, and $10(23.8 \%)$ cases presented between 06:00 and 12:00 (Tab. 1).

Only four (9.5\%) of the 42 patients who were admitted to the emergency department in a serious condition were discharged from the outpatient clinic after 24 hours of emergency follow-up and treatment, while eight (19\%) patients were hospitalised and kept under surveillance for $24-72$ hours. A total of nine patients were treated in the hospital in a period of between 73 hours and one week. In $21(50 \%)$ paediatric cases, hospital stay was longer than one week. Seven of the $42(16.6 \%)$ patients died due to their injuries.

In addition to injuries in abdominal organs, traumas were observed in other body parts due to multiple organ injuries in paediatric blunt abdominal trauma cases analysed here. The liver was the most commonly injured organ in the abdominal region (22 cases, 52.4\%), while the spleen injury was present in $13(31 \%)$ cases. Other injuries associated with blunt abdominal trauma are presented in Table 2. Thirty-one $(73.8 \%)$ patients had abdominal trauma as well as other body injuries, and the most common trauma types were fractures (15 patients, 35.7\%) and lung trauma (12 patients, 28.6\%) (Tab. 2).

The AST values of the patients at the time of admission to the emergency department were between 42 and 482 , with a mean of $158.3 \pm 116$. The ALT values were between 20 and 757, and the mean value was $161.1 \pm 157$. WBC values were between 5000 and 24,000, and the mean was $14,704 \pm 4407$. Mean HGB values measured at admission were found to be $11.09 \pm 2$.3. The t-test was used to infer whether the averages of these four parameters differed between morbidity cases and discharged cases. For ALT $(p=0.001)$, AST $(p=0.001)$, WBC $(p<0.0001)$, and HGB $(p=0.001)$, the mean of all fatal cases was significantly different from the mean of the discharged cases. AST, ALT, and WBC values were significantly higher in the exitus group compared to the discharged group, whereas HGB values were significantly lower (Tab. 3). 


\section{DISCUSSION}

Clinicians' effective and successful evaluation of paediatric blunt abdominal trauma and management of cases depends on the analysis of earlier traumas and the effective use of trauma monitoring parameters. For this purpose, evaluation and reporting of observed cases is of great importance. The present study evaluated specific organ traumas including liver, spleen, intestines, pancreas, and stomach during paediatric blunt abdominal trauma.

The first analyses were conducted on the demographic data of the cases. The current study shows that the majority (76.2\%) of the patients admitted to hospital were male. Similarly, in a previous study, 218 (71.5\%) were reported to be male among 305 blunt thoracic patients [4]. In a retrospective study conducted between 1985 and 1995, $218(83.2 \%)$ of 262 blunt abdominal trauma cases admitted to a major university hospital were reported as males [6]. In addition, when the causes of trauma were analysed in the present study, it was found that the most common cause was falls. Although traffic accidents have been suggested as the main cause in previously published international studies [9], falls have been the major cause in domestic studies $[4,6,10,11]$. As is evident in the present study, the age group most exposed to abdominal blunt trauma is the 13-18-year-olds. Similarly, this age group is the riskiest group in different types of abdominal trauma [10]. The fact that boys are proportionally high and that falls lead to trauma causes, means that the elevated ratio of traumas in those $>10$ years old could be attributed to the cultural playing habits of boys in Turkey.

The mortality rate was found to be around $17 \%$ in this study, which was relatively high compared to previous studies. In a previously reported blunt abdominal trauma study, the mortality rate was $9.1 \%$ [6]. The mortality rate was reported to be $11 \%$ in a study aimed at a similar age group of patients but examining cases of thoracic trauma [4].

The most common pathology in abdominal trauma was liver injury, which was observed in more than half of the cases. In addition, the spleen was the second most common form of injury. Pancreas, stomach, intestine, and perineal injuries were rare, and there were no cases of kidney injury in the current study. In previous studies, spleen injury was recorded as the most common organ injury $[9,11]$.

Various combinations of predictive variables have been used to measure the risk of internal bleeding.
Serum ALT values greater than $125 \mathrm{U} / \mathrm{L}$ or AST values greater than $200 \mathrm{U} / \mathrm{L}$ have been previously proposed [12]. Different results have been reported regarding the use of high ALT and AST values as internal bleeding and risk parameters along with other variables [12-14]. In this study, ALT, AST, WBC, and HGB values which are thought to be predictive and risk parameters were tested for the difference between morbidity cases and discharged patients. All of these parameters were significantly different between the two groups. High ALT, AST, and WBC and low HGB values indicate a risk of internal bleeding, which may be life-threatening in paediatric blunt abdominal trauma.

\section{CONCLUSIONS}

Blunt abdominal injuries are a potential source of morbidity and mortality in paediatric cases. The organs that are damaged during the injury and the parameters that can be used to detect them provide important data for the rapid maintenance and treatment of life-threatening situations.

\section{REFERENCES}

1. Bliss D, Silen M. Pediatric thoracic trauma. Crit Care Med. 2002; 30(11 Suppl): S409-S415, doi: 10.1097/00003246-200211001-00005, indexed in Pubmed: 12528782.

2. Richards JR, Knopf NA, Wang $L$, et al. Blunt abdominal trauma in children: evaluation with emergency US. Radiology. 2002; 222(3): 749-754, doi: 10.1148/radiol.2223010838, indexed in Pubmed: 11867796.

3. Khan RA, Wahab S. Blunt Abdominal Trauma in Children. Problems and Solutions. Springer. 2018, doi: 10.1007/978-981-13-0692-1.

4. Afacan MA, Büyükcam F, Çavuş UY, et al. Acil servise başvuran künt toraks travma vakalarının incelenmesi. Kocatepe Tıp Dergisi. 2012; 13: $19-25$.

5. Ahluwalia T, Toy S, Kennedy C. 39 Use of cognitive task analysis to understand decisionmaking for management of blunt abdominal trauma in children. Ann Emerg Med. 2018; 72(4): S19, doi: 10.1016/j. annemergmed.2018.08.044.

6. Akçay MN, Yıldırgan Mi, Çelebi F, et al. Künt karın travmalarının 10 yıllık retrospektif analizi. 1996.

7. Işıklar $M H$, Allen $R$, Hunter $G$, et al. Künt batın travmalarına bağlı damar yaralanmaları. Ulusal Travma ve Acil Cerrahi Dergisi. 1999; 5(3): 170-174.

8. Akay MA, Gürbüz N, Yayla D, et al. Acil servise başvuran pediatrik travma olgularının değerlendirilmesi. Kocaeli Tıp Dergisi. 2013; 2(3): 1-5.

9. Chirdan LB, Uba AF, Yiltok SJ, et al. Paediatric blunt abdominal trauma: challenges of management in a developing country. Eur J Pediatr Surg. 2007; 17(2): 90-95, doi: 10.1055/s-2007-965008, indexed in Pubmed: 17503300. 
10. Onen A, Kaya M, Cigdem MK, et al. Blunt renal trauma in children with previously undiagnosed pre-existing renal lesions and guidelines for effective initial management of kidney injury. BJU Int. 2002; 89(9): 936-941, doi: 10.1046/j.1464-410x.2002.02787.x, indexed in Pubmed: 12010244.

11. Ozturk H, Dokucu Al, Onen $A$, et al. Non-operative management of isolated solid organ injuries due to blunt abdominal trauma in children: a fifteen-year experience. Eur J Pediatr Surg. 2004; 14(1): 29-34, doi: 10.1055/s-2004-815777, indexed in Pubmed: 15024676.

12. Holmes JF, Sokolove PE, Brant WE, et al. Identification of children with intra-abdominal injuries after blunt trauma. Ann Emerg Med.
2002; 39(5): 500-509, doi: 10.1067/mem.2002.122900, indexed in Pubmed: 11973557.

13. Capraro AJ, Mooney D, Waltzman ML. The use of routine laboratory studies as screening tools in pediatric abdominal trauma. Pediatr Emerg Care. 2006; 22(7): 480-484, doi: 10.1097/01. pec.0000227381.61390.d7, indexed in Pubmed: 16871106.

14. Soyka JM, Martin M, Sloan EP, et al. Diagnostic peritoneal lavage: is an isolated WBC count greater than or equal to $500 / \mathrm{mm} 3$ predictive of intra-abdominal injury requiring celiotomy in blunt trauma patients? J Trauma. 1990; 30(7): 874-879, indexed in Pubmed: 2381004. 